\title{
Mammary analogue secretory carcinoma: a rare salivary gland tumor
}

\author{
Shashikant Anil Pol*, Surinder K. Singhal, Nitin Gupta, Himanshu Bayad
}

Department of ENT, Government Medical College and Hospital, Chandigarh, India

Received: 03 February 2020

Accepted: 17 March 2020

\section{*Correspondence:}

Dr. Shashikant Anil Pol,

E-mail: drshashikantpol@gmail.com

Copyright: ( ) the author(s), publisher and licensee Medip Academy. This is an open-access article distributed under the terms of the Creative Commons Attribution Non-Commercial License, which permits unrestricted non-commercial use, distribution, and reproduction in any medium, provided the original work is properly cited.

\begin{abstract}
Mammary analogue secretary carcinoma are salivary gland tumors similar to secretary carcinoma of breast histologically. It usually affects adults with mean age group of 45 years. Clinically it is usually slow growing, low grade malignancy with favorable prognosis. We are reporting a case of 47 years old female presented with complaints of swelling behind left ear for last 7 years. It was slow growing, painless and persistent. On examination, $4 \mathrm{x} 3 \mathrm{~cm}$ swelling was present just below left ear lobule. It was nontender, firm, irregular in shape with smooth surface with slight mobility and overlying skin pinchable. Fine needle aspiration cytology suggested benign tumor with cystic change. On contrast enhanced computed tomography scan, there was a lobulated hypodense lesion measuring $24 \times 35 \times 32 \mathrm{~mm}$ with internal septations and enhancement of wall in expected location of superficial as well as deep lobe of left parotid gland. Patient underwent left total conservative parotidectomy and histopathology came out to be secretory analogue mammary carcinoma. Subsequently she received post-operative radiotherapy. Patient is on regular follow up and disease free till date. Usually mammary analogue secretory carcinoma is a low-grade malignancy with good prognosis. Immunohistochemistry is confirmatory which shows positivity for S-100 protein and mammaglobin.
\end{abstract}

Keywords: Parotid cyst, Mammary analogue secretary carcinoma, Salivary gland tumors, Total conservative parotidectomy, Post-operative radiotherapy

\section{INTRODUCTION}

Salivary gland tumors sharing histological and genetic (12p13) rearrangements of ETV6 gene, same as secretory carcinoma of the breast, are known as mammary analogue secretary carcinoma (MASC). Though the histologically MASC cases are distinct, still it is difficult to distinguish from low grade salivary duct carcinoma or zymogen-poor acinic cell carcinoma. ${ }^{1}$ Mammary analogue carcinoma usually affects adults of age group 13 to 77 with mean age of 45 years. MASC most commonly presents with slow growing painless mass. MASC shows slight male predilection. Most commonly, it occurs in parotid gland $(70 \%){ }^{2}$ Grossly, MASC is anunen capsulated and well circumscribed tumor with rubbery consistency and variable cystic components. ${ }^{3} \mathrm{On}$ immunohistochemistry, MASC demonstrates S-100 protein and mammaglobin expression. Also, on fluorescence in situ hybridization (FISH), MASC shows ETV6 gene rearrangements. ${ }^{4}$ We have come across an interesting case of MASC of parotid gland. Patient was provisionally diagnosed as benign tumor of parotid gland with cystic change on the basis of cytology and radiological investigation, but later histopathology revealed a rare type of malignancy. Lesion was effectively managed with surgery followed by radiotherapy.

\section{CASE REPORT}

47 years old female presented with complaints of swelling behind left ear for last 7 years. It was slow growing, painless and persistent. There was no history of trauma, fever, decreased mouth opening or facial 
weakness. Patient was a housewife with no history of any systemic illness or addiction. On inspection, a single approximately $4 \times 3 \mathrm{~cm}$ swelling was present just below left ear lobule which was diffuse, smooth surface and non-pulsatile with normal overlying skin. Palpation confirmed inspector findings and it was nontender, firm, irregular in shape having smooth surface with slight mobility and overlying skin was pinchable. Rest of the examination including facial nerve function was within normal limits (Figure 1).

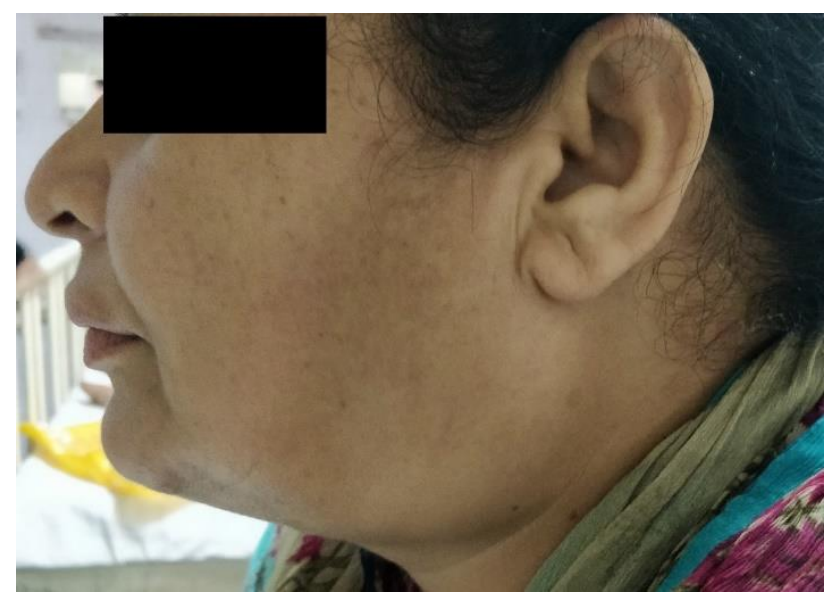

Figure 1: Clinical picture of patient showing diffuse left parotid swelling.

On contrast enhanced computed tomography scan of neck (from base of skull to T4 vertebra), there was a lobulated hypodense lesion measuring 24 x 35 x $32 \mathrm{~mm}$ with internal septations and enhancement of wall in expected location of superficial as well as deep lobe of left parotid gland (Figure 2).

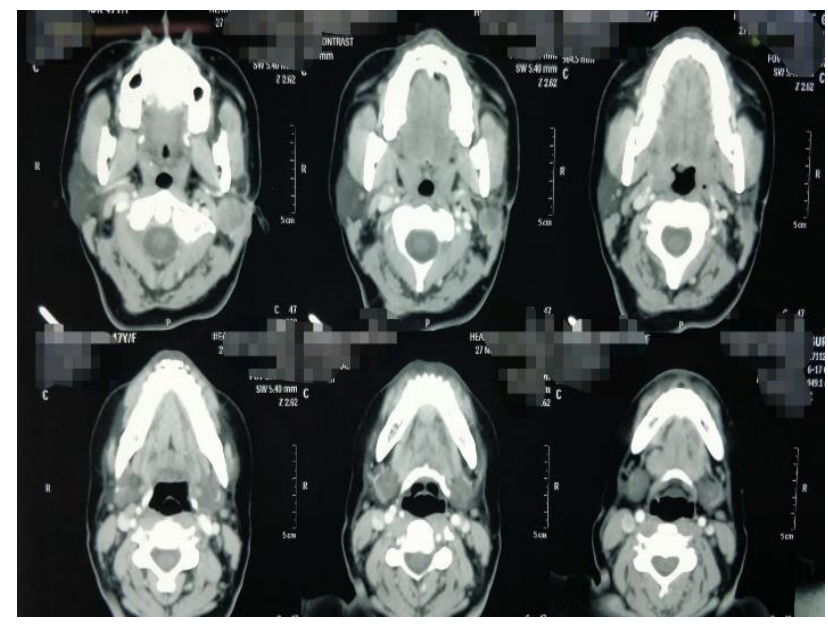

Figure 2: Axial sections of contrast enhanced computed tomography scan of neck (from base of skull to $\mathbf{T} 4$ vertebra) showing left parotid lesion.

Fine needle aspiration cytology (FNAC) revealed scattered foamy macrophages along with a few cohesive clusters of tumor cells. The tumor cells showed round to ovoid nuclei with nuclear overlapping coarse nuclear chromatin. Few of them showed plasmo cytoid morphology and many with intracytoplasmic eosinophilic hyaline globules, suggesting benign tumor with cystic change. Thus, on the basis of FNAC and CT findings provisional diagnosis of a benign lesion of parotid gland with cystic change was made and patient was planned for total conservative parotidectomy under general anaesthesia. After getting written and informed consent from patient and relatives in their own language, patient underwent left total conservative parotidectomy under general anaesthesia (Figure 3).

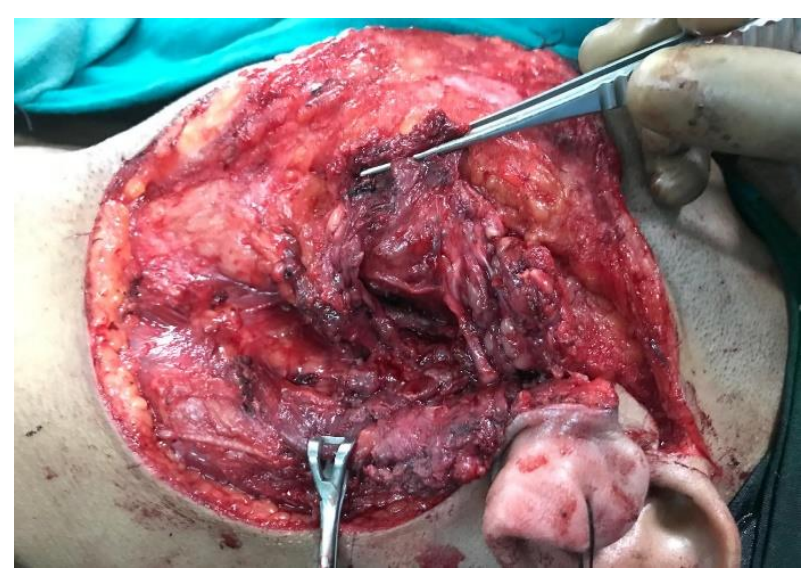

Figure 3: Intraoperative photo showing intact facial nerve trunk with its branches lying close to the tumor of left parotid.

Immediate post-operative period was uneventful and facial nerve function were normal. Patient was satisfactorily discharged after drain removal on post op day 5 and suture removal on $7^{\text {th }}$ post-operative day.

\section{Histopathological examination}

showed partly circumscribed cystic tumor. Tumor was arranged in the form of papillary to microcystic architecture. Tumor cells are cuboidal to polygonal with eosinophilic granular and multinucleated cytoplasm with oval nuclei. Intraluminal and intracellular colloid like material seen. The wall of the cyst showed focal areas of haemorrhage and moderate lymphomononuclear cell infiltrate. Eosinophilic secretions were highlighted by PAS stain and negative with mucicarmine, suggestive of mammary analogue secretary carcinoma with S-100 and mammaglobin positivity and SMA negativity on immunohistochemistry.

As it was a rare entity and was the first ever case of parotid gland MASC reported in our institute, patient was discussed for further management with pathologists and radiation oncologists and patient was then referred for post-operative radiotherapy. Currently, patient is on regular follow-up since last 7 months without any signs of recurrence both clinically and radiologically. 


\section{Patient consent}

As we are working in government institute it is our protocol to take patient and attendant consent both for the procedure and for publication purpose.

\section{DISCUSSION}

First case of salivary MASC was reported by Skalova et al in $2010 .{ }^{1}$ Before its recognition, MASC was usually diagnosed as adenocarcinoma (not otherwise specified) or acinic cell carcinoma (zymogen-poor). ${ }^{3} \mathrm{~S}-100$ protein and mammaglobin exhibit more than $95 \%$ sensitivity for MASC, but lack specificity. ${ }^{5}$ Diffuse strong DOG-1 expression excludes MASC. ${ }^{6}$ ETV6-NTRK3 gene fusion is confirmatory. ${ }^{1,7}$ Difficulty in histological distinction between low grade salivary duct carcinoma and MASC mandates use of immunohistochemistry and FISH to overcome this diagnostic dilemma. The sparse availability of these diagnostic modalities may lead to misdiagnosis which was also been observed in our case. Thus, a chance encounter with these types of lesions should be kept in mind when dealing with salivary gland tumors. Although MASC is low grade malignancy with good prognosis, it may exhibit aggressive course. Surgical excision is the treatment of choice. Local recurrence has been reported after surgical removal in few cases, suggesting need for adjuvant radiotherapy. ${ }^{3}$ We have also done the same thing including surgical excision followed by radiotherapy. Patient is doing well on follow up with no signs of recurrence. Treatments targeting ETV6-NTRK3 chimeric tyrosine kinase should be investigated for future treatment options.

\section{CONCLUSION}

Mammary analogue secretory carcinoma is a new terminology added in late 2010. Usually it is a low-grade malignancy with good prognosis but can have aggressive course. Immunohistochemistry is confirmatory which shows positivity for S-100 protein and mammaglobin. Main stay of treatment is surgical excision. Local recurrence can be there which can be effectively prevented with post-operative radiotherapy which gives patient a disease-free time interval. Accurate knowledge of clinical behavior and prognostic factors of MASC awaits further research.
Funding: No funding sources Conflict of interest: None declared Ethical approval: Not required

\section{REFERENCES}

1. Skalova A, Vanecek T, Sima R. Mammary analogue secretory carcinoma of salivary glands, containing the ETV6-NTRK3 fusion gene: a hitherto undescribed salivary gland tumor entity. Am J Surg Pathol. 2010;34(5):599-608.

2. Sethi R, Kozin E, Remenschneider A. Mammary analogue secretory carcinoma: update on a new diagnosis of salivary gland malignancy. Laryngoscope. 2014;124(1):188-95.

3. Skalova A. Mammary analogue secretory carcinoma of salivary gland origin: an update and expanded morphologic and immunohistochemical spectrum of recently described entity. Head Neck Pathol. 2013;7(1):30-6.

4. Griffith CC, Stelow EB, Saqi A. The cytological features of mammary analogue secretory carcinoma: a series of 6 molecularly confirmed cases. Cancer Cytopathol. 2013;121(5):234-41.

5. Patel KR, Solomon IH, Mofty ESK, Lewis JS, Chernock RD. Mammaglobin and S-100 immunoreactivity in salivary gland carcinomas other than mammary analogue secretory carcinoma. Hum Pathol. 2013;44(11):2501-8.

6. Chenevert J, Duvvuri U, Chiosea S. DOG1: a novel marker of salivary acinar and intercalated duct differentiation. Mod Pathol. 2012;25(7):919-29.

7. Connor A, Ordonez PB, Shago M, Skalova A, Weinreb I. Mammary analog secretory carcinoma of salivary gland origin with the ETV6 gene rearrangement by FISH: expanded morphologic and immunohistochemical spectrum of a recently described entity. Am J Surg Pathol. 2012;36(1):2734.

Cite this article as: Pol SA, Singhal SK, Gupta N, Bayad H. Mammary analogue secretory carcinoma: a rare salivary gland tumor. Int J Otorhinolaryngol Head Neck Surg 2020;6:998-1000. 